\title{
Influence of the parameters of the social force model in the analysis of capacity in public spaces for people with reduced mobility
}

\author{
D. Vásquez, Bachelor of School of Civil Engineering ${ }^{1}$, J. Castro, Bachelor of School of Civil Engineering ${ }^{1}$, \\ M. Silvera, Master of School of Civil Engineering ${ }^{1}$, and F Campos, Master of School of Civil Engineering ${ }^{1}$ \\ ${ }^{1}$ Universidad Peruana de Ciencias Aplicadas, Perú, u201415858@upc.edu.pe, u201321803@upc.edu.pe, \\ manuel.silvera@upc.edu.pe,pccifcam@upc.edu.pe
}

\begin{abstract}
Summary-Pedestrian microsimulation is incompatible with reality when the diversity of pedestrians and their different needs are not considered, which are defined by space, the way of movement and the condition of movement. Therefore, the study of pedestrian displacement has regained importance in transportation planning. This study is focused on the analysis of pedestrian behavior and its connection with the capacity of a public space. For this, the external consultation hall of a hospital has been taken as a case study, due to its pedestrian diversity and space conditions. For the simulation, the 3 most representative characteristics that define the pedestrian behavior during the walk were taken: speed, personal space and trajectories. Likewise, pedestrians were classified into 6 groups, with the objective of assessing their different behaviors. Finally, 5 parameters were selected: Tau, Lambda Mean, Noise, A_soc_Mean and $B \_s o c \_$isotropic, as together they reflect the 3 characteristics of the analysis. As a main result, it was possible to calculate the adequate capacity for the space of 102 people, taking into account the most vulnerable, those with disabilities, so that they have accessibility and move comfortably.
\end{abstract}

Keywords - Social Force; parameters; microsimulation; reduced mobility; pedestrian trajectories; Viswalk

\section{INTRODUCTION}

Pedestrian mobility is difficult to represent in a computerized model, so it often does not reflect reality. This is due to the inherent characteristics of the pedestrian, as well as the evolution of simulation tools. These tools took time to develop after a period of motorization, in which the pedestrian was relegated from interest within the transport system [1]. Thus, the needs of pedestrians were not considered for the design of many urban environments, since transport planners have considered pedestrian movement patterns that do not represent reality [2]. However, at present, non-motorized mobility is seen as a possible solution to the problems caused by vehicles. The reason for this are the benefits such as the care of environmental quality, improving health and as a whole, it generates a better quality of life for people [3].

While it is true, pedestrian behavior is difficult to predict, there are some common characteristics that can be analyzed. These characteristics are given by the connection that exists between the public space and the corporality of a person, which aims to preserve individuality during the trajectory of a pedestrian [4]. A clear example of this is the conservation of distances between one and the other, which is related to the

Digital Object Identifier (DOI):

http://dx.doi.org/10.18687/LACCEI2020.1.1.545

ISBN: 978-958-52071-4-1 ISSN: 2414-6390 personal space that one tries to maintain when perceiving another unknown pedestrian [5].

Social Force is one of the microsimulation models that best suits to represent the behavior of pedestrians, since it is related to pedestrian psychology [6]. In addition, the parameters of this model allow to reflect attitudes similar to pedestrian behavior.

Kielar and Borrmann conducted a pedestrian study at a music festival, published in 2016, in which he analyzes the connection between the speed of a pedestrian and the recognition that makes of the place, in his memory. They affirm that when the pedestrian does not recognize the place where transits, its movement is slower, because its faces new obstacles. Otherwise, if there is recognition, the speed will be greater [7].

In another study of 2018, Cepolina, Menichini and Gonzalez, analyze the internal corridor of the Massachusetts Institute of Technology, regarding the level of individual comfort of a pedestrian, being exposed to the geometry of the surrounding space. It is shown that the availability of space affects the psychology of the pedestrian and is in turn its perception of comfort [8].

Bo-Tao, Chuan-Zhi and Tie-Qiao evaluated a university dining room in China, 2019. This research sought to represent in a simulated model, pedestrian behavior in a state of panic or emergency. In this way, the authors criticize the characteristics of the dining room as capacity. After analyzing the results, it is concluded that the simulated model does not resemble the real situation, since all pedestrians were considered with a homogeneous behavior and without the effect of repulsion forces [9].

The case study, used for the present investigation, was a common space of a hospital, specifically, part of the external consultation corridor. This space is of interest due to the diversity of pedestrians it hosts.

The main objective of this research is to contribute to urban planning studies aimed at pedestrian mobility. In this way, improve the capacity and accessibility of common spaces, considering people with reduced mobility. Accessibility must consider three basic forms of human activity: mobility,

18th LACCEI International Multi-Conference for Engineering, Education, and Technology: "Engineering, Integration, and Alliances for a Sustainable Development" "Hemispheric Cooperation for Competitiveness and Prosperity on a Knowledge-Based Economy", July 27-31, 2020, Virtual Edition. 
communication and understanding [10]. According to an article published by Capbauno it is important to understand and promote that the improvement in accessibility is not an expense, but an investment in human capital and a revaluation of social capital [11].

\section{METHODOLOGY}

This flowchart shows the procedure proposed, through which the study was developed.

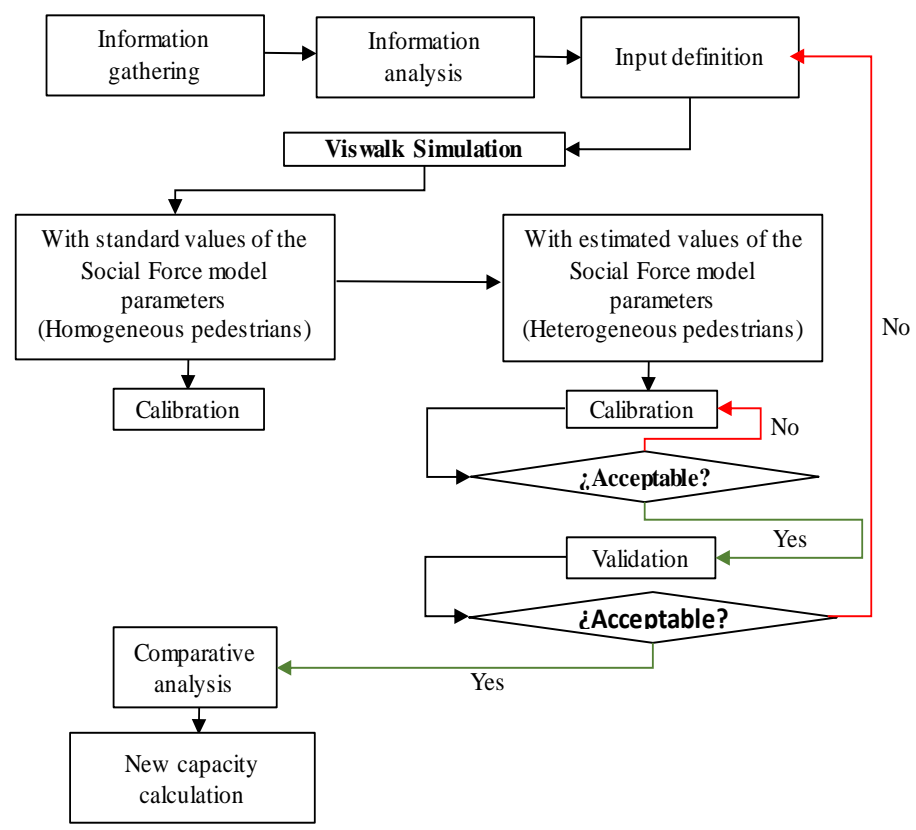

Fig. 1 Research methodology

\section{A. Influence of Social Force parameters}

The social force parameters allow to represent the pedestrian behavior and are defined by mathematical formulas programmed in the software. In this investigation, 5 parameters of the Social Force model were analyzed: tau, lambda, noise, A_soc_mean and B_soc_Iso. Because these are the most convenient in a hospital, according to their characteristics explained below.

- Tau $(\tau)$ : This parameter varies according to the way in which it wants to represent the reaction force caused in a pedestrian by the presence of another. There is a minimum value of 0.005 , but there is no maximum value.

- Lambda_mean ( $\lambda$ _mean): This parameter helps the pedestrian to recognize the obstacles that are in front of him, but not behind him.

- Noise: This parameter is taken into account when the speed of a pedestrian is not constant and remains for some time on an outpatient basis (meaningless or distracted movement).
- A_soc_mean: This parameter has no range of values. This defines the action of giving way, and depends on the speed of two pedestrians.

- B_soc_isotropic: This parameter has no range of values. This defines the distance between pedestrians and reduces their speed.

\section{B. Data collection}

The geometry of the hospital's external consultation corridor was measured, the obstacles in it were identified and the possible trajectories were listed. Accordingly, 16 trajectories or types of displacement were defined, as shown in Fig. 2.

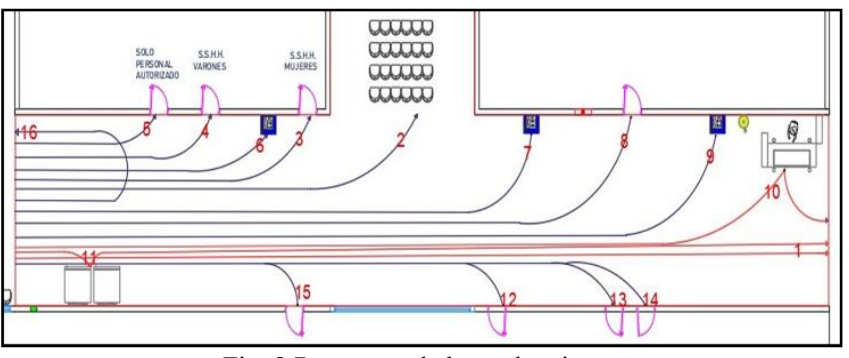

Fig. 2 Routes made by pedestrians

To analyze the behavior of pedestrians in the study area, a filming was made in the hours of greatest influx of people, this was from $2 \mathrm{pm}$ to $6 \mathrm{pm}$. Then, the 15 most critical minutes were selected, to perform the pedestrian count and the results are shown below.

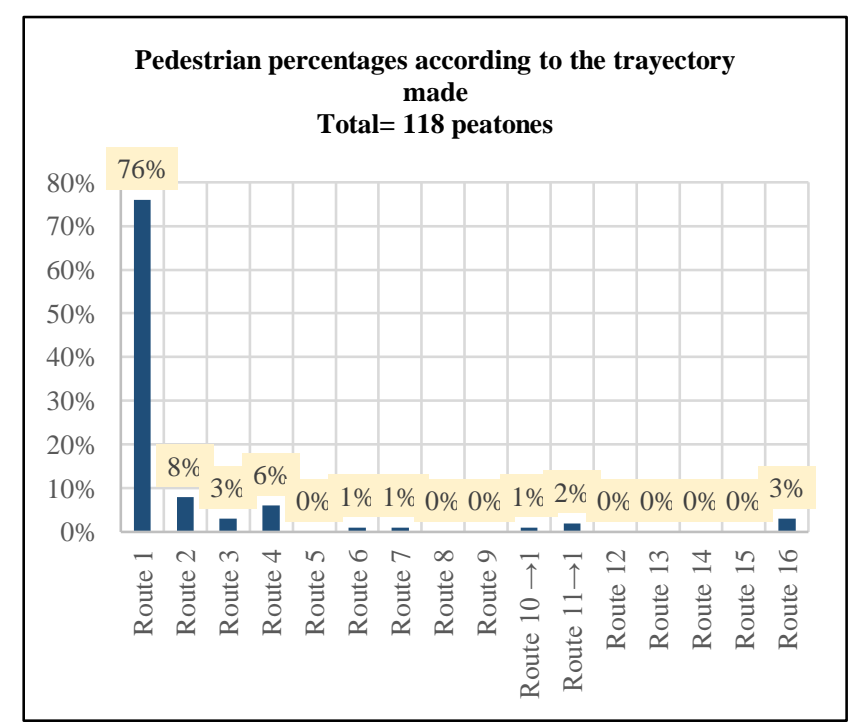

Fig. 3 Percentages of pedestrians according to the trajectory made in count No. 1

The data in Fig. 3 show that route 1 is the most frequent with a representative percentage of $76 \%$, that is 90 pedestrians of the total accounted for (118). 


\section{Classification of user types}

Similarly, by filming, pedestrians could be classified into 6 groups with respect to the space they occupy, speed and walk trajectory.

The first classification was given according to the space they occupy:

TABLE 1

CLASSIFICATION OF PEDESTRIANS ACCORDING TO THE SPACE OCCUPIED

\begin{tabular}{|c|c|c|c|c|}
\hline \multirow{2}{*}{$\begin{array}{c}\text { Type of } \\
\text { pedestrian }\end{array}$} & \multicolumn{2}{|c|}{$\begin{array}{c}\text { Necessary area by } \\
\text { own mass } \\
(\mathbf{a})\end{array}$} & $\begin{array}{c}\text { Comfort and } \\
\text { Safety Factor } \\
(\mathbf{b})\end{array}$ & $\begin{array}{c}\text { Personal space } \\
(\mathbf{a}+\mathbf{b})\end{array}$ \\
\cline { 2 - 5 } & $\begin{array}{c}\text { Width } \\
(\mathrm{m})\end{array}$ & $\begin{array}{c}\text { Long } \\
(\mathrm{m})\end{array}$ & $\begin{array}{c}\text { Area } \\
\left(\mathrm{m}^{2}\right)\end{array}$ & $\begin{array}{c}\text { Area } \\
\left(\mathrm{m}^{2}\right)\end{array}$ \\
\hline Wheelchair & 0.70 & 1.80 & 1.50 & 2.80 \\
\hline Stretcher & 1.40 & 1.90 & 1.50 & 4.20 \\
\hline With child & 0.95 & 0.70 & 1.50 & 2.20 \\
\hline $\begin{array}{c}\text { Average } \\
\text { pedestrian }\end{array}$ & 0.60 & 0.40 & 1.00 & 1.30 \\
\hline $\begin{array}{c}\text { Other } \\
\text { mobility } \\
\text { limitations }\end{array}$ & 0.90 & 1.10 & 1.00 & 2.00 \\
\hline In couple & 1.20 & 0.50 & 1.50 & 2.1 \\
\hline
\end{tabular}

The values of personal space shown in table 1, are a function of the space occupied by people by their own mass and a factor of comfort and safety. The value of this factor is based on biomedical studies on occupational diseases such as tuberculosis, in which it is concluded that from half a meter away, the chances of contagion decrease [12].

The second classification was given based on speeds, which were divided into seven ranges, as shown in table 2 :

TABLE 2

CLASSIFICATION OF PEDESTRIANS ACCORDING TO SPEED

\begin{tabular}{|c|c|c|c|c|c|c|}
\hline \multirow[b]{2}{*}{$\begin{array}{l}\text { Speed ranges } \\
\qquad(\mathrm{m} / \mathrm{s})\end{array}$} & \multicolumn{6}{|c|}{ Number of pedestrians } \\
\hline & 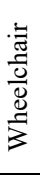 & 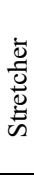 & 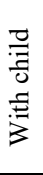 & 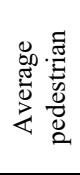 & 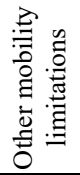 & 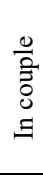 \\
\hline$[0-0.5]$ & 0 & 0 & 0 & 4 & 3 & 1 \\
\hline$[0.51-1]$ & 1 & 1 & 0 & 12 & 3 & 6 \\
\hline$[1.1-1.5]$ & 1 & 0 & 1 & 30 & 1 & 9 \\
\hline$[1.51-2]$ & 0 & 0 & 0 & 15 & 0 & 1 \\
\hline$[2.1-2.5]$ & 1 & 0 & 0 & 2 & 0 & 0 \\
\hline$[2.51-3]$ & 0 & 0 & 0 & 1 & 0 & 0 \\
\hline$[3.1-4]$ & 0 & 0 & 0 & 2 & 0 & 0 \\
\hline
\end{tabular}

In this way you can have a clearer idea of the average speeds that a pedestrian develops according to their conditions to move.
The third classification was given according to the trajectories, thus recognizing the typical routes that each type of pedestrian makes, in the common space of the hospital.

TABLE 3

CLASSIFICATION OF PEDESTRIANS ACCORDING TO THE TRAJECTORY

\begin{tabular}{|c|c|c|c|c|c|c|}
\hline \multicolumn{6}{|c|}{$\begin{array}{l}\text { Trajectories made according to } \\
\text { pedestrian type }\end{array}$} & \multirow[b]{2}{*}{$\begin{array}{l}\text { Wheelchair } \\
\text { Stretcher } \\
\text { With child } \\
\text { Average pedestrian } \\
\text { Other mobility limitations } \\
\text { In Couple }\end{array}$} \\
\hline $\begin{array}{l}1 \\
2 \\
4\end{array}$ & 1 & 4 & $\begin{array}{c}1 \\
2 \\
3 \\
4 \\
6 \\
7 \\
10 \rightarrow 1 \\
11 \rightarrow 1 \\
16\end{array}$ & $\begin{array}{c}1 \\
11 \rightarrow 1 \\
16\end{array}$ & $\begin{array}{c}1 \\
4 \\
16\end{array}$ & \\
\hline
\end{tabular}

The routes defined as $10 \rightarrow 1$ and $11 \rightarrow 1$ represent an intermediate stop within route 1 , in this case, when they stop to buy at the vending machines $(11 \rightarrow 1)$ and the sales post $(10 \rightarrow 1)$.

\section{Modeling}

In Viswalk, the characteristics of the external consultation corridor were entered (see Figure 4), which is an area of connection between environments: offices, toilets, pharmacy and waiting spaces. This scenario was reflected in the Viswalk 9 software.

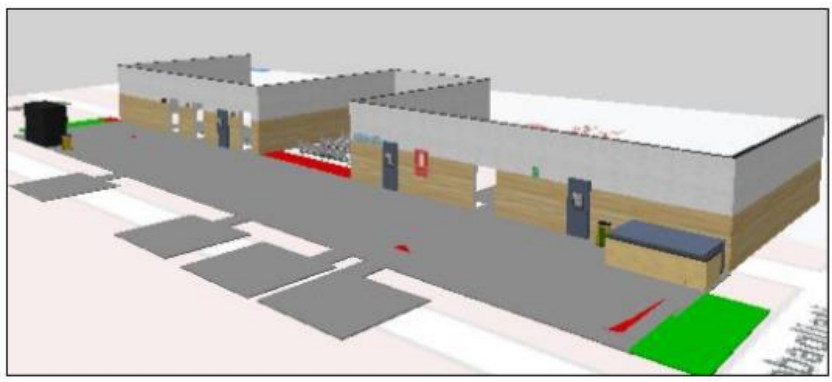

Fig. 4 3D view of the common space

Then, the real situation was simulated with the data collected from the field: trajectories (see Figure 5) and speeds (see Figure 6). In the case of personal space, the dimensions of the pedestrians were entered by own mass, since the safety factor is then calibrated with the software parameters. 


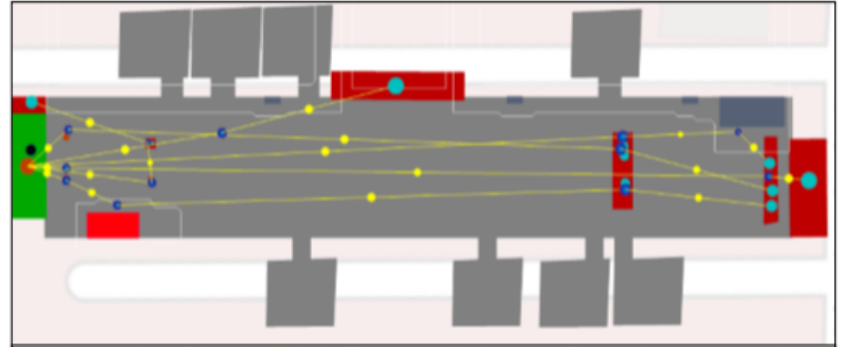

Fig. 5 Trajectories established in Viswalk

With the data in Table 2, the graph of the relative frequencies accumulated in Viswalk is made, to represent pedestrian speeds, as shown in Figure 6 for the average pedestrian.

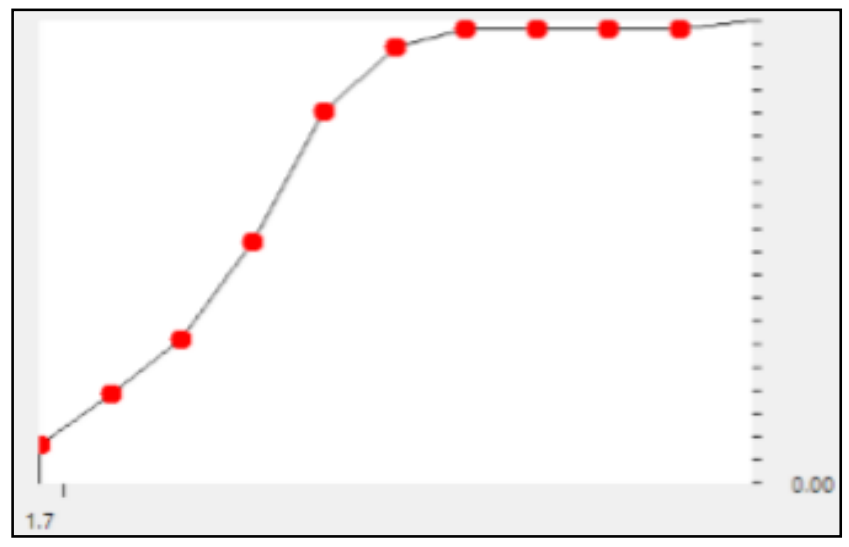

Fig. 6 Cumulative relative frequency of average pedestrian speeds

With the input data already established, the model is calibrated, with respect to the speed variable. In this case, four calibrations resulted. Then, with the results of the last calibration, the StatKey program was used to check the calibration of the model, through the standard deviation.

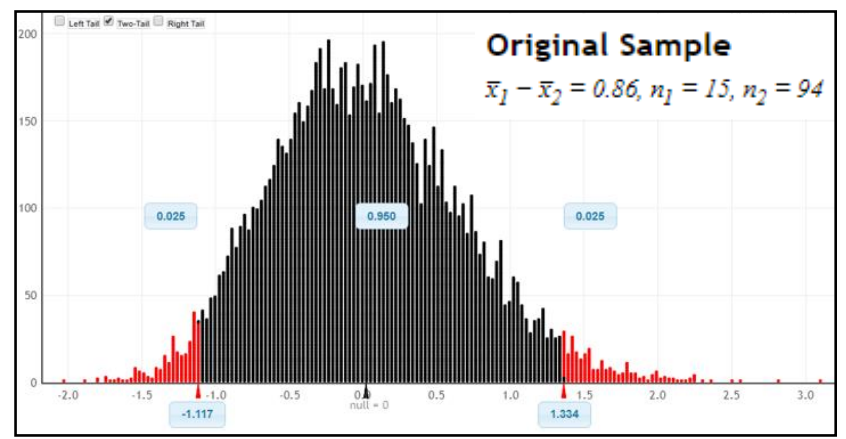

Fig. 7 Final calibration of the model with standard values, in StatKey

Figure 7 shows the difference in means, which is 0.86 , this value being within the range of $-1,117$ and 1,334 , checks the similarity between the model and the actual behavior of pedestrians, visualized in the filming. This result represents that the values of the simulation speed variable are close to those taken in the field and the model is accepted.

In this way, the values of the Social Force model parameters in table 4 are obtained, which make the compatibility of the simulation possible and what was observed in the filming.

TABLE 4

STANDARD VALUES OF THE PARAMETERS OF THE SOCIAL FORCE MODEL

\begin{tabular}{|c|c|c|c|c|c|}
\hline $\begin{array}{c}\text { Type of } \\
\text { pedestrians }\end{array}$ & $\tau$ & $\lambda$ & $\mathrm{N}$ & $\begin{array}{c}\text { A_soc_ } \\
\text { mean }\end{array}$ & $\begin{array}{c}\text { B_soc_- } \\
\text { iso }\end{array}$ \\
\hline Wheelchair & 1.50 & 0.40 & 1.00 & 1.10 & 0.10 \\
\hline Stretcher & 1.50 & 0.40 & 1.00 & 1.10 & 0.10 \\
\hline With child & 0.60 & 0.30 & 1.10 & 1.60 & 0.10 \\
\hline $\begin{array}{c}\text { Average } \\
\text { pedestrian }\end{array}$ & 0.30 & 0.20 & 1.50 & 1.70 & 0.05 \\
\hline $\begin{array}{c}\text { Other mobility } \\
\text { limitations }\end{array}$ & 0.70 & 0.35 & 1.20 & 1.30 & 0.05 \\
\hline In couple & 0.60 & 0.35 & 1.00 & 1.60 & 0.1 \\
\hline
\end{tabular}

It should be noted that the microsimulation model, of this first part, was developed considering characteristics of pedestrian behavior that conform to what was observed in the filming.

Then, it was simulated for the second time, but this time, with the data in tables 1,2 and 3 , on the characterization performed for each type of pedestrian. In this way, we seek to simulate the external consultation space in an idealized way, for the variety of pedestrians. This new model was calibrated, in the same way, with the variable speed.

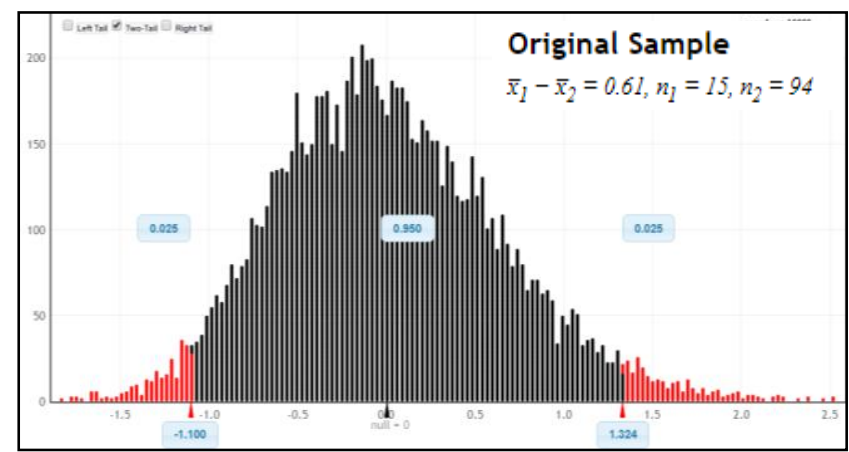

Fig. 8 Final calibration of the model with the pedestrian characterization data

Figure 8 shows the difference of means 0.61 , which is within the range of -1.1 and 1.3 , so the model is accepted.

Once the model has been calibrated, it is validated, for this purpose a new count is made, to verify that the external consultation corridor works with the values of the assigned parameters, for a similar context. 


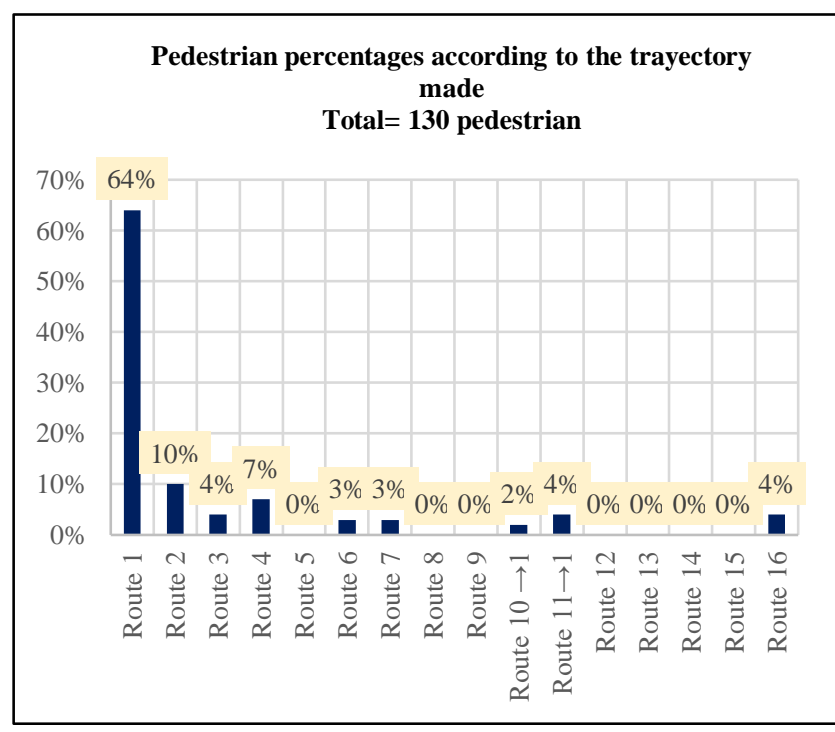

Fig. 9 Percentages of pedestrians according to the trajectory made in count No. 2

By entering these new values into the software, the speed values are obtained according to the type of pedestrian, which are compared with the values collected in the field. To do this, the test is performed in StatKey:

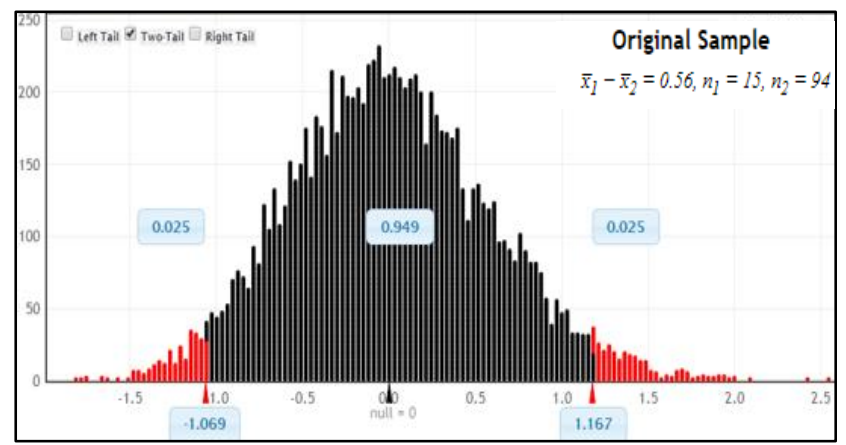

Fig. 10 Final validation of the model with standard values, in StatKey

Figure 10 shows that the difference in means is 0.56 , a value that is within the range of acceptance, between 1.069 and 1.167 , so it is accepted. With these results, the appropriate values can be determined for the Social Force parameters, which are detailed in Table 5.

TABLE 5

ESTIMATED VALUES OF THE PARAMETERS OF THE SOCIAL FORCE MODEL

\begin{tabular}{|c|c|c|c|c|c|}
\hline $\begin{array}{c}\text { Type of } \\
\text { pedestrians }\end{array}$ & $\tau$ & $\lambda$ & $\mathrm{N}$ & $\begin{array}{c}\text { A_soc_- }_{-} \\
\text {mean }\end{array}$ & $\begin{array}{c}\mathrm{B}_{-} \text {isoc_- } \\
\text { iso }\end{array}$ \\
\hline Wheelchair & 0.20 & 0.10 & 0.50 & 0.20 & 0.20 \\
\hline Stretcher & 0.20 & 0.10 & 0.50 & 0.20 & 0.20 \\
\hline With child & 0.30 & 0.17 & 0.80 & 0.35 & 0.24 \\
\hline $\begin{array}{c}\text { Average } \\
\text { pedestrian }\end{array}$ & 0.50 & 0.20 & 1.50 & 0.50 & 0.30 \\
\hline $\begin{array}{c}\text { Other } \\
\text { mobility } \\
\text { limitations }\end{array}$ & 0.25 & 0.15 & 0.70 & 0.30 & 0.23 \\
\hline In couple & 0.40 & 0.20 & 1.20 & 0.40 & 0.25 \\
\hline
\end{tabular}

\section{RESULTS}

The A.130 and A.050 standards indicate two ways to calculate the maximum capacity, the first with a required area per person and the other with the amount of furniture present in the place. In the case of a space for health care, $0.8 \mathrm{~m} 2$ per person or 1 seat per person is established [13], [14]. In order to estimate the current maximum capacity at the site, the following data on the number of people were collected:

TABLE 6

DATA FOR THE MAXIMUM CAPACITY CALCULATION

\begin{tabular}{|c|c|c|}
\hline Hallway area & 245.52 & $\mathrm{~m}^{2}$ \\
\hline People per office & 2.5 & people \\
\hline Pharmacy & 45 & people \\
\hline Outpatient chemotherapy office & 6 & people \\
\hline Wheelchair restrooms & 3 & people \\
\hline
\end{tabular}

Likewise, information was obtained on the number of offices that connect the external consultation corridor, there are 32 environments.

Through the information in table 6 , the number of people who accept the external consultation corridor was obtained, according to their current operation, as shown in table 7 .

TABLE 7

AMOUNT OF PEOPLE ACCORDING TO SPACE ENVIRONMENTS

\begin{tabular}{|c|c|l|}
\hline Total people per office & 80 & people \\
\hline Pharmacy area & 45 & people \\
\hline Disabled restrooms & 3 & people \\
\hline Outpatient chemotherapy office & 6 & people \\
\hline Total people & $\mathbf{1 3 4}$ & people \\
\hline
\end{tabular}

According to the first method indicated by standards A.130 and A.050, with the number of people (134) and the square meters required according to the mentioned standards $(0.8 \mathrm{~m} 2)$, a result of $107.2 \mathrm{~m} 2$ of necessary area was obtained. This calculated area is smaller than the existing area $(245.52 \mathrm{~m} 2)$, so the standards established by the standards are being met.

According to the second method of calculating the capacity, through the number of furniture (waiting chairs), what is shown in table 8 is obtained.

TABLE 8

CURRENT MAXIMUM CAPACITY, ACCORDING TO THE FURNITURE

\begin{tabular}{|c|c|c|}
\hline Waiting chairs in the corridor & 187 & chairs \\
\hline Pharmacy & 15 & chairs \\
\hline Total furniture & $\mathbf{2 0 2}$ & chairs \\
\hline
\end{tabular}


Thus, the capacity of the place, according to the number of existing furniture, is 202 people.

Finally, according to the standards, the most critical value is chosen, that is, the lowest allowable value. In this case, the maximum capacity of the external consultation corridor would be 134 people.

In order to calculate a new value of the maximum capacity, the ideal values were used on the personal spaces, shown in Table 1. Through the application of the same procedure that pose the standards A.130 and A.050, the results described below were obtained.

A value of $326 \mathrm{~m} 2$ was calculated for the area occupied by 134 people in table 7 . While according to the amount of furniture the capacity is 202 people, since the number of chairs does not vary. However, the area is larger than the existing one (326 m2> $245.52 \mathrm{~m} 2)$.

Therefore, it is proposed to reduce the capacity of people allowed in the pharmacy, because said space is the main cause of passability through the external consultation corridor, despite having a reduced space for its current capacity ( 45 people). Thus, the pharmacy's capacity should decrease by 32 units. With this consideration, the new value of the maximum capacity is 102 people, as shown below, in table 9.

TABLE 9

CALCULATION OF THE NEW MAXIMUM CAPACITY OF THE COMMON SPACE

\begin{tabular}{|c|c|l|}
\hline Total people per office & 80 & people \\
\hline Pharmacy area & 13 & people \\
\hline Disabled restrooms & 3 & people \\
\hline Outpatient chemotherapy office & 6 & people \\
\hline Maximum calculated capacity & $\mathbf{1 0 2}$ & people \\
\hline
\end{tabular}

\section{A. Discussion of Results}

In space planning, the maximum capacity of people is calculated based on existing regulations, A.130 and A.050. In the case of the external consultation corridor, the result is 134 people. This value causes the corridor to have accessibility features, based on homogeneous pedestrians. However, the reality of society is that people are heterogeneous and space becomes inaccessible to the most vulnerable: people with disabilities. Therefore, in this study, ideal personal space values are proposed for each type of pedestrian. Given this, a maximum capacity of 102 people was obtained.

\section{CONCLUSIONS}

The Social Force parameters are directly related to pedestrian behavior, compared to social environments (space and other people). In this study, we sought to incorporate the analysis of the parameters A_soc_Mean and B_soc_Iso, since these represent the action of giving way and conserving personal space, respectively.

For the determination of personal spaces, the dimension was taken into account by its own mass and a comfort/safety factor, whose value was $1 \mathrm{~m} 2$ for pedestrians who move individually. While for those who move in a group, the factor was $1.5 \mathrm{~m} 2$. These values were assigned according to a study of tuberculosis as an occupational disease, in 2014.

Appropriate values were obtained for the model parameters: tau, Lambda mean, noise, Asoc_Mean and B_soc_isotropic, which vary when characterizing pedestrians according to the space they occupy, speeds and trajectories. These values are shown in table 5.

The maximum adequate capacity was calculated based on the values proposed as personal space, according to the type of pedestrian. The result of this calculation is 102 people, that is, $24 \%$ lower than the current capacity (134), which is favorable since, in this way, pedestrians can move comfortably and safely with respect to their health.

Finally, as a recommendation for future planning on pedestrian mobility in public spaces, it is recommended to deepen the pedestrian characterization in greater detail. In this way, to achieve realism in detail in the simulations.

\section{REFERENCES}

[1] F. Guío, "Flujos Peatonales en Infraestructuras Continuas: Marco Conceptual y Modelos Representativos," Revista Virtual Universidad Católica del Norte, no. 29, pp. 179-203, Febrero - Mayo 2010.

[2] T. Vlastos, et al, "Peatones: Seguridad Vial, Espacio Urbano y Salud," International Transport Forum, Abril 2011.

[3] A. Fernández and H. Hernández, "Study of pedestrian mobility in an urban center: a case in Costa Rica," Geographic Magazine of Central America, no. 62, June 2019.

[4] M. Aguilar, "Urban Walking and Sociability. Traces from Mexico City," Alteridades, vol. 26, no. 52, July - December 2016.

L. Álvarez, "Collective Intelligence Model of Pedestrian Systems",

[5] doctoral thesis, Universidad Distrital Francisco José de Caldas, 2016. G. Velázquez, "Multi-agent System to Characterize Collective Behaviors in Pedestrian Traffic", thesis for the purpose of

[6] Master's degree, Benemérita Universidad Autónoma de Puebla, 2017. P. Kielar and A. Borrmann, "Modeling Pedestrians Interest in Locations: A concept to Improve Simulation of Pedestrian

[7] Destination Choice," Simulation Modeling Practice and Theory, vol. 61, pp. 47-62, February 2016.

E. Cepolina, F. Menichini and P. Gonzalez, "Level of Service of Pedestrian Facilities: Modeling Human Comfort Perception in the

[8] Evaluation of Pedestrian Behavior Patterns," Transportation Research Part F: Traffic Psychology and Behavior, vol. 58, pp. 365381 , October 2018.

[9] T. Tie, X. Chuan y Z. Bo, "Modeling and Simulation of Pedestrian Flow in University Canteen," Simulation Modelling Practice and Theory, vol. 95, pp. 96-111, April 2019 
[10] ElKartu, "Accessibility Diagnosis in the Hospitals of the CAPV for People with Disabilities, "Ararteko, 2017

[11] R. Aprea, et al, "Towards an Accessible City," Cepbauno, September 2017.

[12] A. Mendoza, "Tuberculosis as an Occupational Disease," Peruvian Journal of Experimental Medicine and Public Health, vol. 29, no. 2, pp. 232-236, June 2012.

[13] STANDARD A.130, Security Requirements, 2012 [Online]. Available http://www.construccion.org/normas/rne2012/rne2006.htm

[14] STANDARD A. 050, Health, 2012. [Online]. Available at: http://www.construccion.org/normas/rne2012/rne2006.htm. 